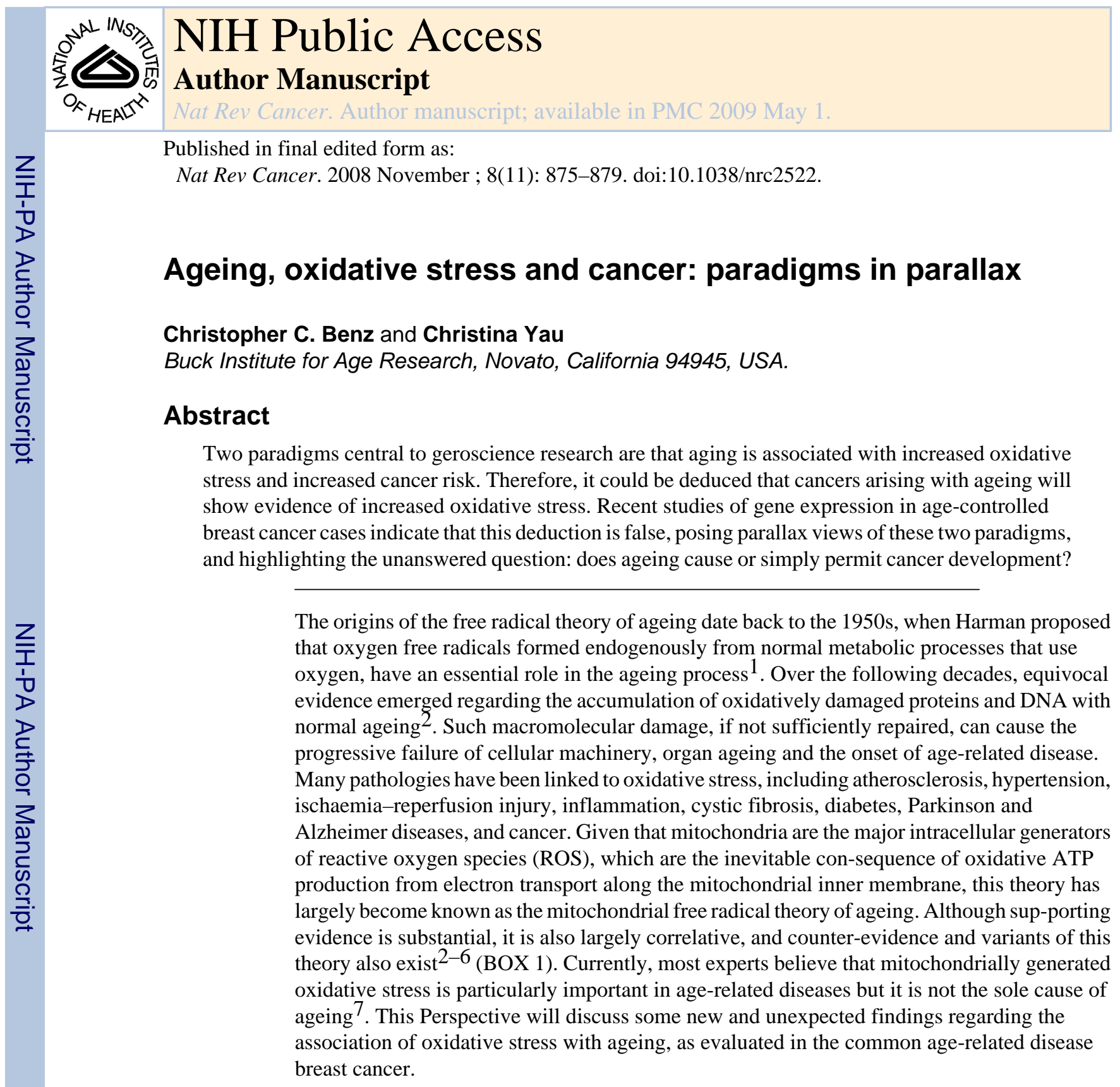

Correspondence to C.C.B. e-mail: cbenz@ buckinstitute.org.

DATABASES

Entrez Gene:

http://www.ncbi.nlm.nih.gov/entrez/query.fcgi?db=gene

BCL2

National cancer institute: http://www.cancer.gov

breast cancer

UniProtKB:

http://www.uniprot.org/

endothelin 2 | ER | PR | RANK | SP1 | SRC | thymidine phosphorylase | TGFß |

FURTHER INFORMATION

C. C. Benz's homepage:

http://www.buckinstitute.org/site/index.php?Itemid=96\&id=103\&option=com_content\&task=view

TFSEARCH:

http://www.cbrc.jp/research/db/TFSEARCH.html

ALL LINKS ARE ACTIVE IN THE ONLINE PDF 


\section{Ageing, breast cancer and epigenetics}

Even in animals with vastly different lifespans, the incidence of malignancies generally increases with age. Overall, the cancer incidence in humans increases exponentially with age, with $75 \%$ of newly diagnosed cases occurring in susceptible populations aged 55 years or older, which supports the epidemiological conclusion that age is the strongest demographic risk factor for most human malignancies 8,9 . Given the worrying social, economic and medical consequences of an ageing worldwide population, there is a pressing need to understand the biological link or links between cancer and ageing. Despite the awareness that breast cancer and other epithelial cancers are primarily age-related diseases, molecular and cellular hypotheses explaining the relation-ship between cancer and ageing have only recently emerged ${ }^{10-13}$. At the subcellular level, normal human ageing has been linked to increased genomic instability ${ }^{14,15}$, global and promoter-specific epigenetic changes 16,17 , and the altered expression of genes involved in cell division and extracellular matrix remodeling 14 , 15. These associations have led to the hypothesis that the cancer-prone phenotype of an older individual results from the combined effects of cumulative mutational load, increased epigenetic gene silencing, telomere dysfunction and an altered stromal milieu ${ }^{18}$. However, clinical assessment of this hypothesis is challenging, as human malignancies such as breast cancer are phenotypically and genotypically heterogeneous. This heterogeneity must be accounted for in any study design that tries to evaluate differences between early- and lateonset forms of the same cancer. When one prospectivxely designed study evaluated early- and late-onset forms of the same histological type of sporadic human breast cancer, oestrogen receptor (ER)-positive breast cancer, the conclusion that the biology of this disease was indeed age-dependent was tempered by a surprising lack of support for the more general cancer-ageing hypothesis ${ }^{19}$. Rather than displaying a 'mutator' phenotype predisposed to genetic instability, accelerated proliferation and more aggressive growth, late-onset ER-positive breast cancers, like many other late-onset human malignancies, appear less aggressive and are associated with a better patient prognosis than early-onset forms of histologically identical ER-positive breast cancers. Remarkably, this prospective study showed that during the normal female lifespan ER-positive breast cancers that arose over 30 years apart did so by fundamentally different epigenetic programmes and not by any detectable differences in genomic mechanisms ${ }^{19}$. In addition, an age signature composed of 128 genes that were differentially expressed between these early- and late-onset breast cancers proved to be $>80 \%$ accurate at discerning younger ER-positive breast cancers from older ER-positive breast cancers in two other independent data sets ${ }^{19}$. Do these epigenetic differences simply reflect age-associated changes in the mammary gland ${ }^{20}$ or can they be explained by the accumulated effects of oxidative stress thought to accompany ageing?

\section{Breast cancer and oxidative stress}

As a putative aetiological factor for both ageing and age-related diseases such as ER-positive breast cancer, oxidative stress is an attractive mechanism with which to explain age-dependent differences in gene expression and cancer biology. Although there is a variety of evidence that suggests that reactive oxygen and nitrogen species contribute to the age-related development of cancers, the cellular sources and carcinogenic mechanisms of these molecules remain unclear $^{21}$. ROS are critical mediators of growth factor receptor signalling 22 and are involved in oestrogen-inducible cancer cell proliferation 23,24 . Not only has the carcinogenic potential of oestrogen exposure been attributed to its oxidation chemistry 25,26 , but oxidative stress pathways activated during cell immortalization and transformation have also been correlated with clinical prognosis in patients with breast cancer ${ }^{27}$. Non-transformed breast epithelial cells experience variable fluctuations in the production of ROS from mitochondrial respiration, peroxisomal $\beta$-oxidation and cytochrome $\mathrm{P} 450$ xenobiotic metabolism ${ }^{28}$. In transformed breast epithelial cells, constitutively activated mitogenic pathways increase intracellular ROS 
production. Transformed metabolic pathways, including increased thymidine phosphorylase expression ${ }^{29}$ and the lacto-peroxidase metabolism of oestrogen ${ }^{30}$ further increase the levels of endogenous ROS. Inadequate tumour neovascularization results in excess oxidative stress as well as glucose deprivation, hypoxia-activating kinase cascades and decreasing antioxidant defences ${ }^{31,32}$. In turn, hypoxia stimulates the expression of chemoattractants such as endothelin 2 in breast cancer ${ }^{33}$, which recruit ROS-producing macrophages that accumulate within the hypoxic regions of various tumour types ${ }^{34}$. Whether it results from organ ageing, endogenous metabolites, malignant transformation pathways or rapid neoplastic growth and metabolism (BOX 2), oxidative stress accompanies breast cancer development and progression to varying degrees, and may therefore be a plausible underlying mechanism for much of the biological and clinical diversity of ER-positive breast cancers. How can oxidative stress alter aspects of tumour biology, such as the endocrine pathways that drive ER-positive breast cancer?

\section{Box 1|Mitochondrial free radical theory of ageing}

In 1956, Denham Harman first proposed that the oxygen free radicals that are endogenously formed from normal metabolic processes in a variety of organisms cause ageing. By 1972, Harman recognized the dominant role of mitochondria in the generation of intracellular reactive oxygen species (ROS) and revamped his proposal into the mitochondrial free radical theory of ageing. With accumulating evidence, and following decades of studies that have involved both invertebrate and vertebrate model systems, there is continued controversy over whether an accumulation of macromolecular damage caused by chronic ROS production limits mammalian lifespan or whether it primarily contributes to the onset of age-related disease. Accepted refinements to this theory now include the chemical participation of reactive nitrogen species (RNS) as well as ROS, recognition that mitochondrial (mt) DNA damage also accumulates with ageing, and appreciation that the balance of intracellular antioxidant and macromolecular repair mechanisms is crucial in determining the cell fate responses to both acute and chronic oxidative stress. It is also important to note that the free radical theory of ageing is not mutually exclusive of other ageing mechanisms (for example, cell senescence, telomere shortening and genomic instability).

Evidence in support of the mitochondrial free radical ageing theory in mammals includes the following:

- mitochondrial ROS production and mtDNA damage (for example, deletions, mutations and base modifications) increase with age in various mammals, including mice and humans

- injection of chemically uncoupled or aged mitochondria induces cellular degeneration of young cells

- $\quad$ knock-in mice with catalase overexpression localized to the mitochondria exhibit reduced levels of mtDNA damage and have an extended lifespan

- caloric restriction reduces mitochondrial ROS production and mtDNA damage and extends lifespan

Evidence that challenges the mitochondrial free radical ageing theory in mammals includes the following:

- transgenic mice that express an error-prone mtDNA polymerase show accelerated signs of ageing and have a decreased lifespan but are not subject to ROS overproduction or oxidative stress 
knockout mice heterozygous for the superoxidase dismutase 2 gene have increased oxidative damage in their nuclear DNA and mtDNA, but exhibit neither signs of accelerated ageing nor a reduced lifespan

\section{Oxidative stress and ER activity}

In addition to DNA damage, there are at least two major consequences of excess ROS production for proteins that affect ER path-ways and the endocrine responsiveness of ERpositive breast cancer: direct oxidative injury to protein structure and ROS-induced kinase signalling. Among the intracellular proteins that are most vulnerable to direct oxidant damage are redox-sensitive nuclear transcription factors, such as $\mathrm{ER}^{35}$ and SP1 (REF 36), whose zinc finger cysteine residues are readily oxidized preventing their DNA-binding function. In ERpositive breast cancers, loss of SP1 DNA-binding activity has been correlated with ageing in association with an increase in the levels of the oxidative stress marker phospho-ERK5 (extracellular signal-related kinase 5, also known as mitogen-activated protein kinase 7 $(\text { MAPK7) })^{37}$ in the tumour. Although a complete loss of the DNA-binding function of the ER that is extracted from primary human breast cancers has not been specifically linked to ageing, this loss has been shown to occur in up to one-third of all ER-positive primary breast cancers and has been correlated with loss of progester-one receptor (PR) expression ${ }^{38}$. because the DNA-binding and transactivating functions of both ER and SP1 are needed for the optimal oestrogenic stimulation of genes such as $P R$ and BCL2, ER-positive breast cancers that have been subjected to sufficient levels of oxidative stress would be expected to show suppressed expression of $P R, B C L 2$ and other oestrogen-inducible genes. The second major consequence of oxidative stress is its association with kinase-dependent signal transduction. In addition to their role in the mediation of growth factor receptor signalling, ROS directly inhibit protein tyrosine phosphatases and thereby stimulate SRC, Janus kinase, Ras family members, protein kinase $\mathrm{C}$ and MAPK signalling 39 . These activated kinase pathways are known to modulate ER activity 40 and have been implicated in endocrine resistance ${ }^{41-44}$. In particular, excess MAPK signal-ling in ER-positive breast cancer cells impairs oestrogen-inducible gene transcription 45 and induces a profile of gene expression similar to that of ER-negative breast cancer cells ${ }^{46}$. Thus, oxidative stress can potentially alter the phenotype of an ER-positive breast cancer, in some cases to such an extent that the endocrine responsiveness of the tumour is lost.

\section{Box 2|Cancer and oxidative stress}

Oxidative stress in the form of excess reactive oxygen species (ROS) or reactive nitrogen species (RNS) can have either deleterious or beneficial effects on a cell, and may be generated by intracellular or extracellular sources. Oxidative stress may cause carcinogenesis by mutating nuclear or mitochondrial DNA, or by causing structural damage of intracellular lipids and proteins. A growing tumour mass may also produce intracellular and extracellular oxidative stress that can transiently or permanently modify its malignant features.

Endogenous sources of tumour ROS or RNS include an impaired mitochondrial genome or proteome, supporting the Warburg hypothesis; activated extra-mitochondrial growth and metabolism pathways; and xenobiotic metabolism.

Exogenous sources of tumour ROS or RNS include ischaemia and reperfusion; inadequate neovascularization; inflammatory cell infiltrate; and activated or damaged stroma. 


\section{Oxidant gene signatures}

Is there clinical evidence for the presence of oxidative stress in ER-positive human breast cancers? Although many gene expression studies have attempted to identify the suite of endocrine-responsive genes expressed in ER-positive breast cancers $47-51$, only one study tried to delineate a subset of endocrine-responsive genes that were also susceptible to modulation by oxidative stress in order to identify and characterize oxidatively stressed ER-positive breast cancers ${ }^{52}$. In this recent study, an ER-positive human breast cancer cell line was subjected to either oestrogen deprivation or ER knockdown and profiled to identify a complete set of genes regulated by oestrogen and ER (designated oestrogen+ER). In addition, the cell line was subjected to stress by three different chemical oxidants (diamide, hydrogen peroxide and menadione), and profiled in order to produce an oxidant signature. The intersection of both the oestrogen+ER and oxidant gene signatures yielded an oxidant-oestrogen+ER signature that was composed of 62 endocrine-responsive genes that were commonly susceptible to the different forms of oxidative stress. Network analysis of the oxidant-oestrogen+ER gene signature from this study highlighted the activation of cancer pathways that regulate cell growth and invasion ${ }^{52}$. The signature derived from the model was used to interrogate a public repository of expression microarray data that characterized 394 ER-positive primary breast cancers, and look for correlations with tumour parameters, patient age at diagnosis and survival outcome. ER-positive breast cancers with higher expression levels of this oxidant-oestrogen +ER gene signature showed a loss of PR expression, high tumour grade and reduced patient survival ${ }^{52}$.Given the link between ageing and oxidative stress, and the expectation that excess levels of oxidative stress would be evident in the breast cancers that arose in older individuals, it was surprising that the ER-positive breast cancers that were diagnosed at an older age did not show higher levels of expression of either the endocrine-specific oxidant-oestrogen+ER signature or the more general ER-independent oxidant signature. In fact, a more refined experimental analysis indicated that oxidative stress was more evident in the ER-positive breast cancers that were diag-nosed at a younger age than those that were diagnosed at an older age ${ }^{52}$.

\section{Shared TNF and TGF $\beta$ pathways}

The fact that the most common forms of breast cancer that arise later in life lack evidence of oxidative stress suggests that the putative link between organ ageing and oxidative stress is obscured by the presence of malignancy-transforming metabolic pathways and cellular environments that generate excess ROS. This notion is consistent with two other observations that relate to ER-positive breast cancers and their proliferative potential: first, breast cancers that are enriched for the oxidant-oestrogen+ER signature have higher expression levels of cell proliferation genes than breast cancers that are not enriched for the signature ${ }^{52}$; and, second, early-onset ER-positive breast cancers have higher expression levels of cell proliferation genes than late-onset breast cancers ${ }^{19}$. Tumours with greater proliferative potential have increased levels of intracellular ROS production owing to excessive growth factor signalling, and are also subjected to increased extracellular ROS production from repetitive cycles of ischaemia and reperfusion as neovascularization attempts to keep up with the rapidly expanding tumour mass. If tumour proliferation and growth rates largely explain breast cancer oxidative stress, and both oxidative stress and proliferation gene signatures are more characteristic of earlyonset breast cancers, then it might be possible to identify other tumour-associated pathways that are shared by both early-onset and oxidatively stressed ER-positive breast cancers. Comparative network analysis of the age $\mathrm{e}^{19}$ and oxidant-oestrogen+ER ${ }^{52}$ gene signatures reveals two such pathways, the tumour necrosis factor (TNF) and transforming growth factor$\beta$ (TGF $\beta$ ) signalling pathways, which are common to both oxidatively stressed and early-onset ER-positive breast cancers (FIG. 1). Interestingly, signals from RANK (receptor activator of nuclear factor $\mathrm{\kappa B}(\mathrm{NF \kappa B})$ ), a TNF receptor superfamily member that is commonly implicated 
in breast cancer, and ligand-stimulated TGF $\beta$ receptors converge to activate intracellular $\mathrm{NF \kappa B}$ and AP1 (FIG. 2). These transcription factor complexes stimulate gene expression programmes that enhance breast cancer cell survival, proliferation, invasiveness and angiogenesis ${ }^{53}$. Indeed, analysis of the proximal promoter regions $(2.5 \mathrm{~kb})$ of the age and oxidant-oestrogen+ER signature genes shown in FIG. 1 indicates that at least 75\% of these TNF- or TGF $\beta$-regulated genes have either AP1 or NFkB consensus binding elements. both early-onset ${ }^{19}$ and oxidatively stressed ${ }^{52}$ ER-positive breast cancers are associated with an increased risk of metastatic recurrence and reduced patient survival. In addition, ER-positive breast cancers with activation of both $\mathrm{NF \kappa B}$ and AP1 are known to be associated with poor patient prognosis and resistance to endocrine therapy ${ }^{54}$. Therefore, this comparative network analysis provides a supporting rationale for the development of NFKB and AP1 inhibitors to treat early-onset ER-positive breast cancers that have a more aggressive and treatment-resistant clinical phenotype due at least in part to oxidative stress.

\section{Evolving paradigms}

Does ageing cause or simply permit cancer development? Despite a long-standing awareness that breast cancer and other cancers are primarily age-related and the general belief that ageing predisposes to cancer development, the nascent field of geroscience is only beginning to inform oncology of the relationship between cancer and ageing. Therefore, the molecular and cellular hypotheses posited to explain this relationship remain largely untested ${ }^{10-13}$. Additional age cohort studies of the type described above for ER-positive breast cancer 19,20 are needed to generalize about the age-dependent biological differences that drive ER-negative breast cancer, as well as other age-related epithelial malignancies. There is growing epidemiological evidence that cancer incidence decelerates or is even suppressed after the age of 80 , and experimental investigation of this theory may substantially modify the currently accepted paradigm that ageing promotes cancer development ${ }^{55}$. Is oxidative stress a cause or consequence of ageing, and is such oxidative stress manifested in all ageing organs or in a few? The same cause-effect question may be asked of the mechanistic relationship between oxidative stress and cancer development. If increasing mitochondrial dysfunction promotes normal cell ageing, and excess ROS from increased growth factor signalling and ischaemia-reperfusion injury promotes cancer cell aggressiveness, is there any mechanistic commonality between these disparate cell fates that are linked to oxidative stress? Aged, oxidatively stressed and senescent stroma are permissive for malignant epithelial transformation in various experimental models 56 . However, human organs that are at risk for age-related malignancies such as breast cancer have not been studied sufficiently to determine whether such stromal changes or senescent cell populations actually predate and promote human cancer in vivo. It is now apparent that many late-onset malignancies such as ER-positive breast cancer are biologically and clinically more indolent than their earlier-onset counterparts. The increase in the incidence of these late-onset malignancies up to the age of 80 may reflect the existence of a more permissive stromal environment that enables the emergence of cancers that would be unable to thrive in younger hosts. If cancer aggressiveness decreases progressively with ageing and out of pace with its increasing incidence, then perhaps an inflection point is ultimately reached in the human lifespan, whereupon a microscopic malignancy becomes unable to make a clinical appearance. This challenging area of biology and oncology must continue to be examined and questioned from many different angles, as parallax views of our evolving cancer and ageing paradigms are needed to provide a sufficient depth of understanding to successfully confront the growing health-care burden of our ageing population.

\section{References}

1. Harman D. Aging: a theory based on free radical and radiation chemistry. J. Gerontol 1956;11:298300. [PubMed: 13332224] 
2. Muller FL, Lustgarten MS, Jang Y, Richardson A, Van Remmen H. Trends in oxidative aging theories. Free Radic. Biol. Med 2007;43:477-503. [PubMed: 17640558]

3. Finkel T, Holbrook NJ. Oxidants, oxidative stress and the biology of ageing. Nature 2000;408:239247. [PubMed: 11089981]

4. Raha S, Robinson BH. Mitochondria, oxygen free radicals, disease and ageing. Trends Biochem. Sci 2000;25:502-508. [PubMed: 11050436]

5. Krishnan KJ, Greaves LC, Reeve AK, Turnbull D. The ageing mitochondrial genome. Nucleic Acids Res 2007;35:7399-7405. [PubMed: 17913753]

6. Gruber J, Schaffer S, Halliwell B. The mitochondrial free radical theory of ageing - where do we stand? Front Biosci 2008;13:6554-6479. [PubMed: 18508680]

7. Vijg J, Campisi J. Puzzles, promises and a cure for ageing. Nature 2008;454:1065-1071. [PubMed: 18756247]

8. Edwards B, et al. Annual report to the nation on the status of cancer, 1973-1999, featuring implications of age and aging on U.S. cancer burden. Cancer 2002;94:2766-2792. [PubMed: 12173348]

9. Thun, M.; Jemal, A. Cancer Epidemiology. Hamilton: BC Decker; 2006.

10. Ershler WB, Longo DL. Aging and cancer: issues of basic and clinical science. J. Natl Cancer Inst 1997;89:1489-1497. [PubMed: 9337345]

11. Balducci L, Ershler WB. Cancer and ageing: a nexus at several levels. Nature Rev. Cancer 2005;5:655-662. [PubMed: 16056261]

12. Benz CC, Campisi J, Cohen HJ, Ershler WB, Irminger-Finger I. Meeting report: translational research at the aging and cancer interface. Cancer Res 2007;67:4560-4563. [PubMed: 17510382]

13. Pawelec G, Solana R. Are cancer and aging different sides of the same coin? Conference on cancer and ageing. EMBO Rep 2008;9:234-238. [PubMed: 18259218]

14. Geigl JB, et al. Analysis of gene expression patterns and chromosomal changes associated with aging. Cancer Res 2004;64:8550-8557. [PubMed: 15574761]

15. Ly DH, Lockhart DJ, Lerner RA, Schultz PG. Mitotic misregulation and human aging. Science 2000;287:2486-2492. [PubMed: 10741968]

16. Issa JP. Aging, DNA methylation and cancer. Crit. Rev. Oncol. Hematol 1999;32:31-43. [PubMed: 10586353]

17. Richardson B. Impact of aging on DNA methylation. Ageing Res. Rev 2003;2:245-261. [PubMed: 12726774]

18. DePinho RA. The age of cancer. Nature 2000;408:248-254. [PubMed: 11089982]

19. Yau C, et al. Aging impacts transcriptomes but not genomes of hormone-dependent breast cancers. Breast Cancer Res 2007;9:R59. [PubMed: 17850661]

20. Benz CC. Impact of aging on the biology of breast cancer. Crit. Rev. Oncol. Hematol 2008;66:6574. [PubMed: 17949989]

21. Halliwell B. Oxidative stress and cancer: have we moved forward? Biochem. J 2007;401:1-11. [PubMed: 17150040]

22. Lander HM. An essential role for free radicals and derived species in signal transduction. FASEB J 1997;11:118-124. [PubMed: 9039953]

23. Felty Q, Singh KP, Roy D. Estrogen-induced $\mathrm{G}_{1} / \mathrm{S}$ transition of $\mathrm{G}_{0}$-arrested estrogen-dependent breast cancer cells is regulated by mitochondrial oxidant signaling. Oncogene 2005;24:4883-4893. [PubMed: 15897899]

24. Oberley TD, Allen RG, Schultz JL, Lauchner LJ. Antioxidant enzymes and steroid-induced proliferation of kidney tubular cells. Free Radic. Biol. Med 1991;10:79-83. [PubMed: 2050299]

25. Patel MM, Bhat HK. Differential oxidant potential of carcinogenic and weakly carcinogenic estrogens: Involvement of metabolic activation and cytochrome P450. J. Biochem. Mol. Toxicol 2004;18:37-42. [PubMed: 14994278]

26. Bhat HK, Calaf G, Hei TK, Loya T, Vadgama JV. Critical role of oxidative stress in estrogen-induced carcinogenesis. Proc. Natl Acad. Sci. USA 2003;100:3913-3918. [PubMed: 12655060]

27. Dairkee SH, et al. Oxidative stress pathways high-lighted in tumor cell immortalization: association with breast cancer outcome. Oncogene 2007;26:6269-6279. [PubMed: 17471242] 
28. Beckman KB, Ames BN. The free radical theory of aging matures. Physiol. Rev 1998;78:547-581. [PubMed: 9562038]

29. Moghaddam A, et al. Thymidine phosphorylase is angiogenic and promotes tumor growth. Proc. Natl Acad. Sci. USA 1995;92:998-1002. [PubMed: 7532308]

30. Sipe HJ Jr, Jordan SJ, Hanna PM, Mason RP. The metabolism of $17 \beta$-estradiol by lactoperoxidase: a possible source of oxidative stress in breast cancer. Carcinogenesis 1994;15:2637-2643. [PubMed: 7955118]

31. Blackburn RV, et al. Metabolic oxidative stress activates signal transduction and gene expression during glucose deprivation in human tumor cells. Free Radic. Biol. Med 1999;26:419-430. [PubMed: 9895234]

32. Li C, Jackson RM. Reactive species mechanisms of cellular hypoxia-reoxygenation injury. Am. J. Physiol. Cell Physiol 2002;282:C227-C241. [PubMed: 11788333]

33. Grimshaw MJ, Naylor S, Balkwill FR. Endothelin-2 is a hypoxia-induced autocrine survival factor for breast tumor cells. Mol. Cancer Ther 2002;1:1273-1281. [PubMed: 12516960]

34. Grimshaw MJ, Wilson JL, Balkwill FR. Endothelin-2 is a macrophage chemoattractant: implications for macrophage distribution in tumors. Eur. J. Immunol 2002;32:2393-2400. [PubMed: 12207323]

35. Liang X, et al. Oxidant stress impaired DNA-binding of estrogen receptor from human breast cancer. Mol. Cell Endocrinol 1998;146:151-161. [PubMed: 10022773]

36. Wu X, Bishopric NH, Discher DJ, Murphy BJ, Webster KA. Physical and functional sensitivity of zinc finger transcription factors to redox change. Mol. Cell Biol 1996;16:1035-1046. [PubMed: 8622648]

37. Quong J, et al. Age-dependent changes in breast cancer hormone receptors and oxidant stress markers. Breast Cancer Res. Treat 2002;76:221-236. [PubMed: 12462383]

38. Scott GK, Kushner P, Vigne JL, Benz CC. Truncated forms of DNA-binding estrogen receptors in human breast cancer. J. Clin. Invest 1991;88:700-706. [PubMed: 1864980]

39. Valko M, Rhodes CJ, Moncol J, Izakovic M, Mazur M. Free radicals, metals and antioxidants in oxidative stress-induced cancer. Chem. Biol. Interact 2006;160:1-40. [PubMed: 16430879]

40. Levin ER. Bidirectional signaling between the estrogen receptor and the epidermal growth factor receptor. Mol. Endocrinol 2003;17:309-317. [PubMed: 12554774]

41. Kirkegaard T, et al. AKT activation predicts outcome in breast cancer patients treated with tamoxifen. J. Pathol 2005;207:139-146. [PubMed: 16088978]

42. Knowlden JM, et al. Elevated levels of epidermal growth factor receptor/c-erbB2 heterodimers mediate an autocrine growth regulatory pathway in tamoxifenresistant MCF-7 Cells. Endocrinology 2003;144:1032-1044. [PubMed: 12586780]

43. Nabha SM, et al. Upregulation of PKC- $\delta$ contributes to antiestrogen resistance in mammary tumor cells. Oncogene 2005;24:3166-3176. [PubMed: 15735693]

44. Gee JM, et al. Epidermal growth factor receptor/HER2/insulin-like growth factor receptor signalling and oestrogen receptor activity in clinical breast cancer. Endocr. Relat. Cancer 2005;12:S99-S111. [PubMed: 16113104]

45. Oh AS, et al. Hyperactivation of MAPK induces loss of ER $\alpha$ expression in breast cancer cells. Mol. Endocrinol 2001;15:1344-1359. [PubMed: 11463858]

46. Creighton CJ, et al. Activation of mitogen-activated protein kinase in estrogen receptor $\alpha$-positive breast cancer cells in vitro induces an in vivo molecular phenotype of estrogen receptor $\alpha$-negative human breast tumors. Cancer Res 2006;66:3903-3911. [PubMed: 16585219]

47. Creighton CJ, et al. Genes regulated by estrogen in breast tumor cells in vitro are similarly regulated in vivo. Genome Biol 2006;7:R28. [PubMed: 16606439]

48. Coser KR, et al. Global analysis of ligand sensitivity of estrogen inducible and suppressible genes in MCF7/BUS breast cancer cells by DNA microarray. Proc. Natl Acad. Sci. USA 2003;1000:1399413999. [PubMed: 14610279]

49. Lin CY, et al. Discovery of estrogen receptor $\alpha$ target genes and response elements in breast tumor cells. Genome Biol 2004;5:R66. [PubMed: 15345050]

50. Oh DS, et al. Estrogen-regulated genes predict survival in hormone receptor-positive breast cancers. J. Clin. Oncol 2006;24:1656-1664. [PubMed: 16505416] 
51. Vendrell JA, et al. Estrogen regulation in human breast cancer cells of new downstream gene targets involved in estrogen metabolism, cell proliferation and cell transformation. J. Mol. Endocrinol 2004;32:397-414. [PubMed: 15072547]

52. Yau C, Benz CC. Genes responsive to both oxidant stress and loss of estrogen receptor (ER) function identify a poor prognosis group of ER-positive primary breast cancers. Breast Cancer Res 2008;10:R61. [PubMed: 18631401]

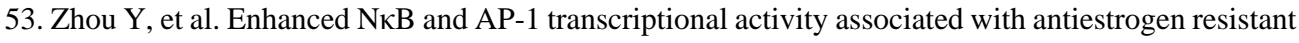
breast cancer. BMC Cancer 2007;7:59. [PubMed: 17407600]

54. Zhou Y, et al. Activation of nuclear factor $\kappa \mathrm{B}(\mathrm{NF \kappa B})$ identifies a high-risk subset of hormonedependent breast cancers. Int. J. Biochem. Cell Biol 2005;37:1130-1144. [PubMed: 15743683]

55. Harding C, Pompei F, Lee EE, Wilson R. Cancer suppression at old age. Cancer Res 2008;68:44654478. [PubMed: 18519710]

56. Campisi J, d'Adda di Fagagna F. Cellular senescence: when bad things happen to good cells. Nature Rev. Mol. Cell Biol 2007;8:729-740. [PubMed: 17667954]

57. Zhang H, Ramanathan Y, Soteropoulos P, Recce ML, Toias PP. EZ-Retrieve: a web-server for batch retrieval of coordinate-specified human DNA sequences and underscoring putative transcription factor-binding sites. Nucleic Acid Res 2002;30:e121. [PubMed: 12409480]

58. Heinemeyer T, et al. Databases on transcriptional regulation: TRANSFAC, TRRD and COMPEL. Nucleic Acid Res 1998;26:364-370.

\section{Acknowledgments}

The authors' work is supported in part by National Institutes of Health grants R01-AG020521, R01-CA71468, P01AG025901, U54-RR024346/RL1-AG032113, P50-CA58207, and Hazel P. Munroe memorial funding to the Buck Institute. 

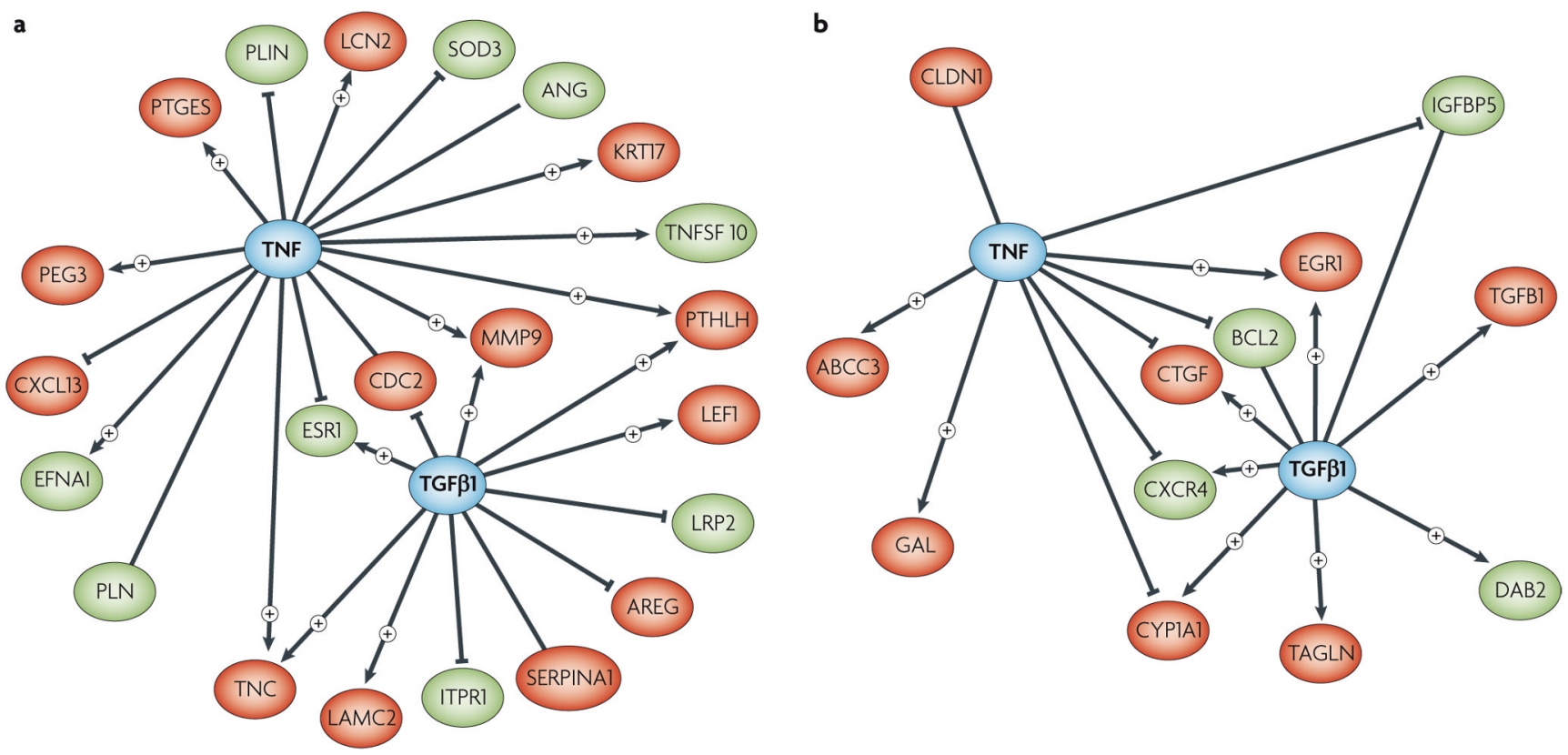

Figure 1. Pathways that are shared by oxidatively stressed and earlyonset breast cancers Top-scoring gene networks, which are determined by ingenuity Pathways systems analysis of age $^{19}$ and oxidative stress ${ }^{52}$ gene signatures in oestrogen receptor (ER)-positive breast cancers, commonly identify tumour necrosis factor (TNF) and transforming growth factor- $\beta$ (TGF $\beta$ ) pathway nodes. Ariadne Pathway studio was used to identify the respective TNF- and TGF $\beta$ - regulated (direct or indirect) targets from the 126-gene age signature (a) and the 62gene oxidant-oestrogen+ER signature (intersection of oestrogen- and ER-regulated signature and oxidant-stressed signature; b). Regulatory directions were determined from primary references provided by Pathway studio, with positive $(+)$ regulatory directions denoted by arrow-heads and negative regulatory directions denoted by bars (lines without either arrowheads or bars indicate ambiguous regulatory direction). Unigene symbols in red ovals indicate signature genes that are upregulated by oxidative stress or in early-onset breast cancer; those in green ovals indicate signature genes that are downregulated by oxidative stress or in early-onset breast cancer. At least $75 \%$ of the signature genes that have been shown to be regulated by TNF and TGF $\beta(\mathbf{a}, \mathbf{b})$ contain nuclear factor $\kappa \mathrm{B}(\mathrm{NF} \kappa \mathrm{B})$ or $\mathrm{AP} 1$ consensus element binding sites within their proximal promoters, as determined by EZRetrieve and TFSEARCH ${ }^{57-58}$ (see TFSEARCH in Further information). ABCC3, ATP-binding cassette 3; ANG, angiogenin; AREG, amphiregulin; CDC2, cell division cycle 2; CLDN1, claudin 1; CTGF, connective tissue growth factor; CXCR4, chemokine (C-X-C motif) receptor 4; CXCL13, chemokine (C-X-C motif) ligand 13; CYP1A1, cytochrome P450 1A1; EGR1, early growth response 1; DAB2, disabled homologue 2; EFNA1, ephrin A1; ESR1, oestrogen receptor 1; GAL, galanin prepropeptide; IGFBP5, insulin-like growth factor binding protein 5; ITPR1, inositol 1,4,5-triphosphate receptor 1; KRT17, kera-tin 17; LAMC2, laminin- $\gamma 2$; LCN2, lipocalin 2; LEF1, lymphoid enhancer-binding factor 1; LRP2, low density lipoproteinrelated protein 2; MMP9, matrix metalloproteinase 9; PLN, phospholamban; PLIN, perilipin; PTHLH, parathyroid hormone-like hormone; PTGES, prostaglandin E synthase; SERPINA1, serpin peptidase inhibitor 1; SOD3, superoxide dismutase 3; TAGLN, transgelin; TNC, tenascin C; TNFSF10, tumour necrosis factor (ligand) superfamily 10. 


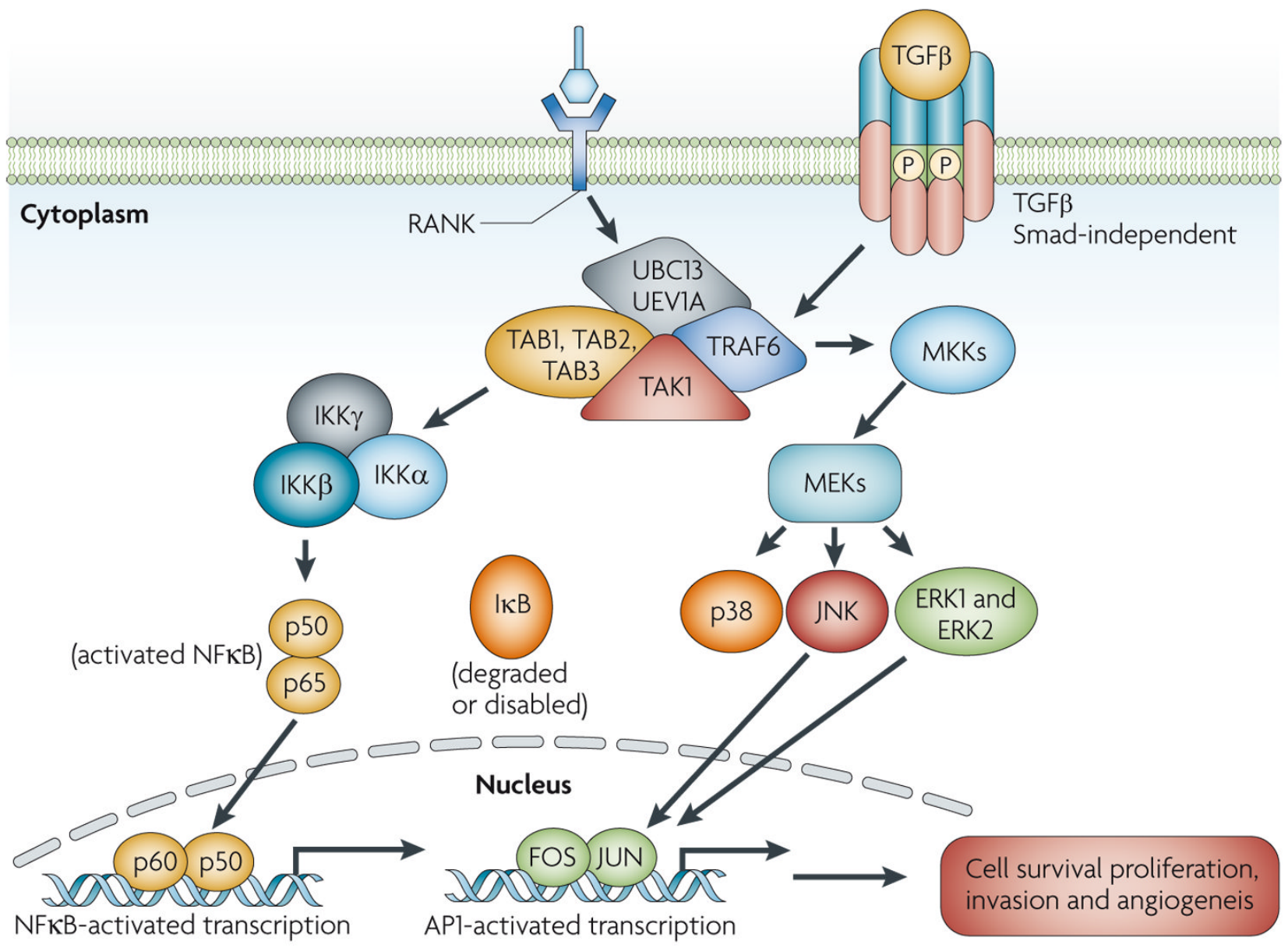

Figure 2. Signalling pathways in oxidatively stressed and early onset breast cancers

RANK (receptor activator of nuclear factor $\kappa \mathrm{B}(\mathrm{NF} \kappa \mathrm{B})$ ) is a tumour necrosis factor (TNF) receptor superfamily member that is commonly implicated in breast cancer, and ligandstimulated RANK and transforming growth factor- $\beta$ (TGF $\beta$ ) receptors are shown as convergent signal transduction pathways that are capable of activating intracellular NFkB and AP1 transcription factor complexes. These can induce gene expression programmes that promote breast cancer cell survival, proliferation, invasiveness and angiogenesis. ERK, extracellular

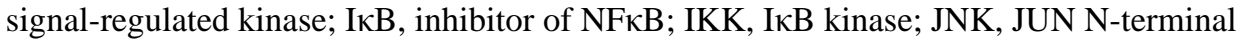
kinase; MEK, MAPK/ERK kinase; MKK, mitogen-activated protein kinase kinase; TRAF6, TNF receptor-associated factor 6; UBC13, ubiquitin-conjugating enzyme E2 13; UEV1A, ubiquitin-conjugating enzyme E2 variant $1 \mathrm{~A}$. 